\title{
Developmental Neurobiology of the Zebrafish
}

\author{
Judith S. Eisen \\ Institute of Neuroscience, University of Oregon, Eugene, Oregon 97403
}

How does the nervous system develop? This problem has intrigued embryologists for more than a century. In fact, early investigators formulated many of the fundamental questions about how the nervous system arises, how neurons acquire their identities, and how neuronal processes find and form synapses with appropriate target cells. To answer these questions, it would be ideal to have a single species with which cellular, molecular, and genetic analyses could be carried out on individually identified neurons and their associated cells as they develop and generate a complex nervous system. The zebrafish (Brachydanio rerio) has the potential to be such a species. In this essay, I will discuss aspects of the zebrafish that make its embryo an excellent material for developmental studies, results that have extended our knowledge of nervous system development, and future prospects for this work.

The virtues of the zebrafish embryo for the study of nervous system development

The zebrafish embryo is an excellent material for cellular studies of neuronal development because it is nearly transparent; thus, developing neurons can be visualized and studied in situ. The zebrafish embryo shares its favorable optical properties, which result from sequestration of yolk granules into a single, giant yolk cell, with the embryos of related teleost species, such as the Japanese medaka (Kuwada, 1986), the killifish, and the rosy barb (Thorogood and Wood, 1987). Because of this optical transparency, individual cells, including individual neurons, can be visualized by means of differential interference contrast optics throughout much of the course of embryonic development. The earliest neurons arise in the embryo in small numbers, and many of them can be identified as unique individuals. It is possible, therefore, to follow the development of an identified neuron from birth through the outgrowth of processes and formation of synaptic connections.

The pioneering work of George Streisinger provided a foundation for genetic and molecular studies of neuronal development in the embryonic zebrafish. Streisinger developed techniques for producing clonal strains of homozygous diploid zebrafish that are free of lethal mutations, for introducing new mutations into zebrafish, and for mapping these mutations (Streisinger et al., 1981, 1986; Chakrabarti et al., 1983; Walker and Streisinger, 1983; Streisinger, 1984). Clonal strains provide a genetically homogeneous background for studying the effects

\footnotetext{
I thank Carl Fulwiler, David Grunwald, Charles Kimmel, Peter O'Day, and Monte Westerfield for many fruitful discussions and for comments on earlier versions of the manuscript, and Pat Edwards for typing. Research in my lab is supported by NIH, NSF, and The Procter and Gamble Company.

Copyright (C) 1991 Society for Neuroscience 0270-6474/91/110311-07\$03.00/0
}

of new mutations, because all of the individuals of a clonal strain are of the same genotype. Because fertilization of the egg and the entire course of development occur outside of the body of the mother, embryos can be examined for mutant phenotypes at all developmental stages. In addition, because of the optical transparency of the embryo, simple morphological screens can identify gene mutations that affect early patterning of the embryonic nervous system, or later events such as extension of processes or formation of synaptic connections.

To screen for new mutations, eggs from mutagenized clonal females can be activated with genetically impotent sperm to produce haploid embryos that are viable throughout the embryonic period; the first mitotic or second meiotic cleavage can be suppressed in such embryos by treatment with heat or pressure, respectively, to produce homozygous diploids. Thus, haploid or homozygous diploid embryos can be screened for new recessive mutations directly in the $F_{1}$ generation, obviating the need to raise individual mutant $F_{1}$ heterozygotes and cross them to obtain $\mathrm{F}_{2}$ generation homozygotes for screening. The availability of the procedure offsets the disadvantage presented by the long generation time of the zebrafish, at least compared with that of species such as Drosophila and Caenorhabditis elegans, which are commonly used to study the genetics of neuronal development. Once individuals carrying interesting mutations are identified, they can be bred at frequent intervals; up to several hundred progeny are obtained from each breeding. Recessive lethal mutations can be propagated by outcrossing to wild types (e.g., see Grunwald et al., 1988), thus maintaining the mutant allele in heterozygous form. Mutant lines can be preserved by freezing sperm. Finally, because many neurons can be individually identified, it should be possible to localize the action of specific genes to particular neurons.

How does the nervous system arise?

Position and ancestry of a cell as determinants of its fate Charles Kimmel and his collaborators have examined whether the fates of embryonic cells of the zebrafish are determined by their positions or by their line of ancestry, where the term fate is defined as the differentiated cell types formed by the progeny that normally arise from an embryonic cell. They observed that the first few cell divisions of the embryo are regular and give rise to a stereotyped pattern of cells, called blastomeres (Kimmel and Law, 1985a). The regularity of the early divisions raised the possibility that the zebrafish embryo might arise from an invariant pattern of cell divisions, or cell lineage, in which the same cell would arise by the same division pattern in every embryo; this kind of invariant cell lineage occurs in the nematode C. elegans (Sulston et al., 1983). By labeling single blastomeres with nontoxic fluorescent dyes that are passed on to 
their progeny at each cleavage, Kimmel and Warga (1986) were able to follow the division patterns and movements of their marked progeny in living embryos. They found that blastomeres arising from the same pattern of cell divisions in different embryos gave rise to progeny with different fates and located in different positions. From these observations, they concluded that the cell lineage of the embryo is indeterminate (Kimmel and Warga, 1987); thus, the line of ancestry of a cell cannot be the sole determinant of its fate.

Although cell fate in the zebrafish embryo is indeterminate, restrictions in the range of cell fates do occur during embryogenesis that limit the type of tissues to which an individual cell normally contributes progeny. The first such restriction occurs at about the midblastula stage, when cells that contribute to an extraembryonic tissue are segregated from cells that contribute to the embryo proper (Kimmel and Law, 1985b). Restrictions in the range of fates of embryonic lineages occur later, during a stage called gastrulation, when cells are actively migrating and rearranging their positions within the embryo (Kimmel et al., 1990).

Kimmel et al. (1990) constructed a fate map for the zebrafish embryo by mapping the correspondence between the position of a cell at the onset of gastrulation and the fates of that cell's progeny later in development. The fate map of the zebrafish embryo shows many similarities to the fate map for amphibian embryos. In both cases, there is a direct correspondence between the position a cell occupies at the onset of gastrulation and the type of tissue its progeny will form. Thus, it appears that the position of a cell within the gastrula, rather than its ancestry, determines its ultimate fate.

To learn whether position-associated restrictions of cell fate are due to commitment of cells to particular fates will require transplanting individual cells to new positions within the gastrula. If the transplanted cells develop in accord with their new positions, they were not committed at the time they were moved; however, if they develop in accord with their sites of origin, they probably were committed at the time they were moved.

\section{Origin of the cells of the nervous system}

What are the relative roles of lineage and position in determining which cells will establish the nervous system? Streisinger and his colleagues used a genetic marking technique to demonstrate that the early lineage of a cell does not determine whether it will contribute progeny to the nervous system. They created genetic mosaic embryos containing a clone of pigmentless (homozygous mutant) cells in a normally pigmented (heterozygous) background by somatic recombination induced by irradiating embryos heterozygous for a recessive pigment mutation. They examined the progeny of recombinant cells in the pigmented retinal epithelium of the eye and found that, in each embryo, this tissue contained patches of pigmentless cells surrounded by pigmented cells. From these data, Streisinger and his colleagues (Streisinger et al., 1989) concluded that the eye arises by the intermixing of the progeny of many different ancestral cells. This finding agrees with those described above and suggests that the lincage of the nervous system is not fixed.

Based on the studies from which they constructed the fate map, Kimmel et al. (1990) found that, during gastrulation, cells that will give rise to the nervous system are segregated from cells that will give rise to other tissues, by moving to separate positions within the developing embryo. Moreover, for cells that are in a position to contribute progeny to the nervous system, there is a direct correspondence between their location at the onset of gastrulation and the region of the nervous system their progeny will populate. For example, forebrain structures arise from a more anterior position than do hindbrain structures. However, because of the extensive rearrangements that take place during gastrulation, it is not possible to predict which cells will be the progenitors of specific neurons. For example, spinal cord interneurons and motoneurons may arise from the same ancestral cell (Kimmel et al., 1990). Taken together, the studies described above show that, like the rest of the embryo, the position of a cell in the gastrula-stage embryo is more important than its lineage in determining whether that cell will participate in establishing the nervous system.

\section{Features of neurons that arise at different times}

Zebrafish neurons arise in 2 temporally distinct waves; the neurons of each wave may subserve different functions in the developing embryo. Neurons of the first wave, termed "primary" neurons (see Kimmel and Westerfield, 1990, for a discussion of the origin of this term and a review), are distinguished by their early development, large sizes, and small number from neurons of the later wave, termed "secondary" neurons. Primary neurons arise during or shortly after gastrulation (Mendelson, 1986a; Myers et al., 1986) and include cells of all functional classes. Primary neurons are the first to extend growth cones; their axons establish the first nerve pathways in the embryo and form a simple scaffold (Wilson et al., 1990) upon which later axons may navigate (Kuwada, 1986; Pike et al., 1989). Within a few hours after axogenesis, primary sensory neurons, primary interneurons, and primary motoneurons begin to establish the synaptic connections that will form the first functional circuitry in the embryo. This circuitry is responsible for generating early behaviors, such as swimming to escape from predators. Perhaps because they are crucial for establishing the early functional circuitry as well as providing the pathways followed by later growth cones, at least some aspects of the development of zebrafish primary neurons may be regulated by different mechanisms from those governing development of later-developing zebrafish neurons or neurons in other vertebrates (see below; Liu and Westerfield, 1990).

In embryos homozygous for the neural degeneration mutation ned-I (Grunwald et al., 1988), the nervous system begins to develop normally, and embryos exhibit normal early behaviors, suggesting that the primary neurons establish functional circuitry. However, during the second day of development, secondary neurons of all functional classes begin to degenerate, while all primary neurons remain viable. Thus, in addition to the morphological and developmental criteria by which the primary and secondary neurons were initially distinguished, they can also be distinguished by genetic criteria. Again, this observation supports the suggestion that there may be fundamental differences between these 2 sets of neurons.

\section{Identification of individual primary neurons}

The small number, large sizes, and characteristic axonal trajectories of the primary neurons have allowed many of these cells to be identified as unique individuals. Although identified neurons such as the Mauthner cell (see Faber and Korn, 1978) have previously been described in vertebrates, it has been commonly assumed that such cells were peculiar to invertebrates. However, recent work from larval and adult zebrafish has shown that many neurons can be individually identified, including specific mo- 
toneurons (Myers, 1985; Westerfield et al., 1986), and interneurons (Kuwada et al., 1990) in the spinal cord, and interneurons in the hindbrain (Metcalfe et al., 1986). These identified neurons are ideally suited for developmental studies because precisely homologous cells can be studied in embryo after embryo. Thus, one does not need to contend with the variability introduced by studying a population of neurons that subserve the same function, but that may be cryptically heterogeneous.

\section{Segmental arrangement of identified neurons}

All vertebrate embryos develop metameric structures called somites that give rise to the segmented axial musculature and vertebrae. The segmented musculature is innervated by a segmented pattern of motor nerves and sensory ganglia that develops in register with the somites. Experimental manipulations in avian embryos suggest that segmentation of these neural elements is imposed by the segmentation of the somites (Keynes and Stern, 1984). Although the motor nerves are overtly segmentally arranged, motoneurons in most vertebrate spinal cords do not appear segmentally organized. This is due to 2 factors: (1) differential growth of the muscles relative to the spinal cord, which causes the somata of the motoneurons to move out of register with the muscle segments innervated by their axons (Westerfield and Eisen, 1985), and (2) extensive overlap between the motoneurons innervating different muscles in vertebrates with a large number of motoneurons.

In the zebrafish, the cell bodies of primary motoneurons remain in register with the muscle segments innervated by their axons even to adulthood (Westerfield et al., 1986). Monoclonal antibodies (mAbs) that specifically label the primary motoneurons early in development, such as the $\mathrm{zn}-1 \mathrm{mAb}$, reveal that these cells have a prominent segmental organization (Hanneman et al., 1988). Some other primary neurons, such as the VeLD primary interneurons (Kuwada et al., 1990) are also segmentally arranged. Early in their development, the somata of the VeLD neurons occupy a ventral location in the spinal cord; this location is very close to the ventral location initially occupied by the somata of the primary motoneurons. However, not all of the primary neurons in the spinal cord show a segmental arrangement. Labeling with another $\mathrm{mAb}$, zn-12, shows that dorsally located Rohon-Beard primary sensory neurons appear not to be segmentally arranged (Metcalfe et al., in press).

Work from zebrafish and other vertebrates has shown that the hindbrain contains 7 conspicuously segmented structures called rhombomeres (Lumsden and Keynes, 1989; Keynes and Lumsden, 1990). Trevarrow et al. (1990) isolated a set of mAbs that reveal a complex repeated pattern of neurons and glia that corresponds to the pattern of rhombomeres in the embryonic zebrafish hindbrain. The identified primary reticulospinal neurons, recognized by the zn-1 and $\mathrm{zn}-12 \mathrm{mAbs}$, are located ventrally at the center of each rhombomere. Dorsally located commissural neurons at the segment borders are labeled by another $\mathrm{mAb}, \mathrm{zn}-5$. The 2 groups of neurons are separated by curtains of glia, recognized by several different mAbs. In fact, of the 37 mAbs whose labeling pattern was examined, 31 showed a segmental pattern in the hindbrain.

The $\mathrm{mAb}$ that reveals the segmental organization of the primary motoncurons in the spinal cord also reveals a segmental distribution of some ventrally located primary neurons in the zebrafish hindbrain (Hanneman et al., 1988). Early in development, the $\mathrm{zn}-1 \mathrm{mAb}$ recognizes individual neurons or small groups of them in 7 discrete hindbrain regions. The distance between the labeled cells corresponds to the length of a spinal segment. Thus, the ventral regions of the spinal cord and hindbrain appear to have a continuous scgmental organization. Developmental studies of the segmentally repeated cells in the hindbrain (Mendelson, 1986b) show that they are the identified primary reticulospinal neurons whose segmental organization has been shown by retrograde transport of HRP (Kimmel et al., 1982; Metcalfe et al., 1986).

Are all of the hindbrain segments equivalent? At least some of the identified reticulospinal neurons appear to be segmentally repeated homologues that show characteristic, segment-specific differences in morphology and development (Metcalfe et al., 1986). Thus, though the hindbrain segments may have initially been equivalent, they probably diverged during evolution (Metcalfe et al., 1986). In invertebrates such as insects and nematodes, differences among segmental homologues arise by remodeling the axons of cells that initially undergo a common developmental program (Bate et al., 1981; Loer et al., 1987; for revicw, sec Kimmel, 1990). The axons of reticulospinal neurons that reside in different hindbrain segments initially extend along different pathways, suggesting that, in this case, the initial control of axonal development is more important than later modifications in generating segment-specific differences between homologues (see Kimmel, 1990).

How do the growth cones of developing neurons find their targets?

\section{Stereotypy and accuracy of growth cone pathfinding}

To establish appropriate synaptic connections, neurons must complete 2 steps. First, they must extend a process into a region of the body containing an appropriate target, and, second, they must form synapses with the correct type and number of target cells. The first step in this process is often referred to as pathfinding, and it involves the extension of a growth cone, the growing tip of a neuronal process, which follows a particular path on its way to its target. Growth cone pathfinding has been studied for several types of primary neurons in the embryonic zebrafish. In most cases, neurons were labeled at a variety of developmental stages with specific mAbs or dyes, and the time course of outgrowth was reconstructed from observations of many different individuals. In these studies, it was found that each type of neuron extends a growth cone along a characteristic, cell-specific pathway; growth cones extend directly to their appropriate targets without making obvious errors. The growth cones of most primary neurons extend for a long distance to reach their targets, suggesting that there may be local and longrange cues that provide pathway guidance. However, the growth cones of sensory neurons of the lateral line comigrate with their targets, as they establish lateral line organs along the body axis (Metcalfe, 1985), suggesting that these growth cones may be in continuous contact with their targets.

To study the dynamic aspects of pathfinding, my colleagues and I labeled individually identified primary motoneurons with vital dyes and observed axonal extension directly in live embryos. We used 2 different labeling techniques in these studies: injection of rhodamine dextran into a precursor blastomere and labeling of individual neurons by application of the lipid-soluble dye $1,1^{\prime}$-dioctodecyl-3,3,3',3'-tetramethylindocarbocyanine perchlorate (Di-I; Honig and Hume, 1986). We found that every muscle segment in the embryonic zebrafish trunk is innervated by 3 or 4 primary motoneurons, each of which is uniquely identifiable by its soma position and the exclusive muscle ter- 
ritory in which it arborizes (Eiscn ct al., 1986, 1990; Myers et al., 1986). Direct, time-lapse observations of axonal outgrowth showed that, within each segment, the primary motoneurons extend their growth cones in a stereotyped sequence, and that the growth cone of each motoneuron extends directly to its functionally appropriate muscle territory without making obvious errors. Thus, as is the case for other zebrafish primary neurons, the growth cones of the primary motoneurons reach their targets by a process of directed pathfinding.

\section{Processes that may contribute to pathfinding}

To investigate the cues that may guide the primary motoneuronal growth cones to their targets, we have taken advantage of our ability to perturb the environment in which these cells are developing and to observe their responses. We have investigated the potential roles of a variety of features, including (1) interactions among identificd primary motoncurons, (2) clectrical activity of the target, (3) absence of the target, and (4) extracellular matrix glycoproteins. We found that some of these features affected growth cone pathfinding, while others appeared to have no effect.

Interactions among primary motoneurons. We investigated the role of interactions among primary motoneurons during axonal outgrowth by ablating individual motoneurons and following the subsequent development of the remaining motoneurons in the same segment. The optical transparency of the embryo makes it possible to recognize the somata of identified primary motoneurons even when they are not labeled (Eisen et al., 1986, 1989). Thus, we were able to ablate unlabeled, identified motoneurons by irradiation with a focused laser microbeam (Eisen et al., 1989), a technique pioneered in C. elegans (Sulston and White, 1980) that has also been applied to pathfinding studies in other invertebrates (Bentley and Caudy, 1983; Keshishian and Bentley, 1983; Bastiani et al., 1985) and fish embryos (Kuwada, 1986). We then labeled the remaining motoneuron or motoneurons in the segment and watched when and where they extended their growth cones. Our results showed that each of the primary motoneurons has an independent ability to carry out proper pathfinding even in the absence of all other primary motoneurons in the same spinal segment (Pike and Eisen, 1990). Thus, interactions among the primary motoneurons do not appear to be required for normal pathfinding.

Not only do interactions among primary motoneurons appear unnecessary for proper pathfinding, but direct observations of axonal branching suggest that motoneurons do not compete for muscle fibers (Liu and Westerfield, 1990). Although main growth cones of the primary motoneurons do not seem to make obvious errors during pathfinding, some secondary branches are made on muscle fibers in inappropriate territories. The time course of retraction of these branches is consistent with a model in which primary motoneurons compete for the innervation of muscle fibers. However, when potential competition is removed by ablating one of the 2 motoneurons, the other motoneuron still withdraws the inappropriate branches, suggesting that, in this case, competition does not determine which muscle fibers individual motoneurons innervate.

Target activity. Interactions between motoneurons and their targets based on target activity are thought to be important for the formation of proper synaptic connections (Purves and Lichtman, 1985). Westerfield and his colleagues investigated the role of activity in pathfinding and synapse formation by zebrafish primary motoneurons by blocking muscle activity pharmaco- logically and genetically. Liu and Westerfield (1990) allowed embryos to develop under conditions in which sodium channels or ACh receptors were blocked and found that pathfinding, synaptogenesis, and the pattern of muscle innervation by the primary motoneurons were normal. Westerfield et al. (1990) examined pathfinding in embryos homozygous for the nicotinic $\mathrm{ACh}$ receptor mutation nic-1, which lack functional $\mathrm{ACh}$ receptors; these embryos do not respond to cholinergic agonists, nor are their muscles detectably labeled by $\alpha$-bungarotoxin or $\mathrm{mAbs}$ directed against $\mathrm{ACh}$ receptor subunits. Despite the absence of functional $\mathrm{ACh}$ receptors, motoneurons in mutant embryos appear to complete proper pathfinding. Morphologically normal neuromuscular junctions were also seen at the fine-structural level. These 2 sets of results suggest that, in this system, transmitter-evoked muscular activity is not important for proper pathfinding and is probably not required for synapse formation.

Absence of the muscle target. Interactions between motoneurons and the muscles they innervate appear to be important for formation of normal motoneuron axonal pathways (Lewis et al., 1981; Tosney, 1987). In zebrafish embryos homozygous for the spadetail mutation spt-1 (Kimmel et al., 1989), the development of the primary motoneurons is abnormal. At least some of these neurons extend growth cones out of the spinal cord, but they form axons that are morphologically aberrant. spt- $1 \mathrm{em}-$ bryos also have severe disruptions of muscle segments in the trunk region that arise because prospective trunk somite cells migrate improperly into the tail rudiment during gastrulation. Thus, trunk muscle segments are absent or contain a greatly reduced number of muscle cells. Ho and Kane (in press) created genetic mosaics and showed that the mutation acts directly to cause prospective trunk muscle cells to migrate improperly during gastrulation. The aberrant morphology of primary motoneuron axons in spadetail embryos might arise in 2 very different ways: The mutation could act directly to alter some intrinsic feature of the primary motoneurons, or it could be the result of an alteration in some feature of their environment that is critical for proper pathfinding, such as the presence of target muscle. To learn whether the mutation acted directly on the motoneurons or was due to loss of target muscle cells, I performed a genetic mosaic analysis by transplanting individual primary motoneurons between mutant and wild-type embryos (J. S. Eisen, unpublished observations). These experiments showed that the mutation does not affect the motoneurons directly, suggesting that their abnormal development is due to the loss of their target muscles.

Extracellular matrix molecules. Extracellular matrix molecules have been implicated as possible pathfinding cues for axonal growth cones (Rogers et al., 1983). Frost and Westerfield (1986) examined the distribution of extracellular matrix molecules in embryonic zebrafish and found that the primary motoneuronal growth cones contact laminin-rich areas of the embryo and avoid fibronectin-rich areas, such as the segmental borders. This observation suggests that fibronectin may pattern the motor axons by determining where they cannot grow (Patterson, 1988). B. Debu, D. Frost, M. Westerfield, and J.S. Eisen (unpublished observations) tested this idea by injecting fibronectin into ectopic locations along the laminin-rich region in which the axons of the primary motoneurons normally grow. The motor axons appeared to avoid the novel, fibronectin-rich areas, as though the presence of the fibronectin prevented them from carrying out normal pathfinding. These experiments sug- 
gest that the presence of fibronectin in the segmental border regions may pattern motor growth cones by preventing them from extending into adjacent muscle segments.

\section{What determines neuronal identity? \\ Position as a determinant of the identity of individual primary motoneurons}

As was mentioned above, the position of a cell in the gastrula specifies the fate of its progeny in terms of which tissues they will populate. However, the exact positions of the progenitors of primary motoneurons within the nervous system primordium are indeterminate. Might the position of a developing neuron after gastrulation determine its individual identity? The primary motoneurons present an ideal system in which to address this question, because there is a consistent relationship between the 2 features that define the individual identity of each cell, its soma position within the spinal cord, and the region of muscle it innervates. To test whether soma position determines the region of muscle a motoneuron will innervate, I transplanted the somata of identified primary motoneurons to new spinal cord positions in the embryo at various developmental stages (Eisen, 1989). Postmitotic motoneurons transplanted at early stages of their development extended their axons into the muscle territories appropriate for their new soma positions. These results suggest that, initially, all primary motoneurons may be equivalent, and that the axonal pathway selected by each cell may, in fact, be dictated by the position of its soma. Thus, soma position appears to be a critical factor in determining motoneuronal identity.

\section{Genetic control of neuronal identity}

Mutational analysis of invertebrates such as Drosophila and $C$. elegans has been instrumental in identifying some of the genes involved in neuronal determination and differentiation (Desai et al., 1988; Doe and Scott, 1988; Chalfie and Au, 1989). A common feature of many of these genes is that they encode transcriptional regulators that affect the expression of specific cellular characteristics. Many of these genes play multiple roles during development, functioning not only in neurons, but also in other cell types. Thus, it seems unlikely that the identity of individual neurons is determined by cell-specific genes, but, rather, that the interplay of several genes contributes to the unique properties of an individual neuron.

Mutational analysis of vertebrate neuronal development is still in its infancy. However, some of the genes that have been identified in Drosophila have expression patterns in vertebrate embryos that suggest that the vertebrate homologues of these genes are good candidates for regulators of vertebrate neuronal development (Stern and Keynes, 1988). In particular, genes that contain a homeobox, a 180-base-pair sequence encoding a putative transcriptional control element, show intriguing spatial and temporal expression patterns in the vertebrate CNS. Fjose has analyzed the structure and function of several homeoboxcontaining genes in the embryonic zebrafish (Eiken et al., 1987; Fjose et al., 1988; Njolstad and Fjose, 1988; Njolstad et al., $1988 \mathrm{a}, \mathrm{b})$. The zebrafish genes have similar spatial and temporal expression patterns to their well-studied murine homologues.

A distinct advantage of analysis of genes important for ncuronal development is the potential for localizing expression to individually identified neurons or to other identified cells. The simple patterning of the zebrafish embryo greatly facilitates such a study. For example, Patel et al. (1989) used an antibody to the homeodomain-containing region of the protein product of the Drosophila engrailed gene to study the expression of this gene in the zebrafish embryo. Within the CNS, cells surrounding the midbrain/hindbrain boundary express this antigen throughout embryogenesis; a similar expression pattern was also seen in chick, mouse, and Xenopus embryos. In addition, within the developing somites, expression of this antigen was localized to the nuclei of 3-4 identified muscle cells (Hatta et al., in press). During pathfinding, the growth cones of the primary motoneurons pause for several hours after contacting these cells (Eisen et al., 1986), suggesting that they may play a role in growth cone guidance. Using the same antibody, Hatta et al. (in press) have found this antigen expressed in the nuclei of cells that develop to form 2 specific jaw muscles; expression occurs before the cells differentiate, but at about the time they become innervated by specific motoneurons. The localization of these antigens to identified muscle cells suggests that homeodomain proteins may play a heretofore undescribed role in establishing muscle identity and in neuromuscular target recognition.

Molven et al. (1990) recently made another novel observation about homeobox-containing genes by examining the expression of an individual gene in a single class of zebrafish primary neurons. They found that a particular homeobox-containing gene called XlHbox 1 was expressed in a graded fashion in RohonBeard primary sensory neurons; within the body region in which the gene is expressed, more rostrally located cells had higher levels of expression than did more caudally located cells. RohonBeard cells outside of this region did not express the gene. This may be the first demonstration that a single neuronal cell type can differentially express a putative regulatory gene according to its position along the body axis. Furthermore, their results suggest the exciting possibility that positional information along the body axis might control expression of some homeoboxcontaining genes.

\section{Future prospects}

To understand how a complex nervous system is generated, we must learn about the genetic and molecular mechanisms that underlie the development of individual neurons and how these processes are regulated by cellular interactions. Studies of the embryonic zebrafish have begun to address these issues. A growing number of investigators are beginning to study the zebrafish embryo, and work underway in their laboratories is expanding the techniques that can be used to study neuronal development. For example, Stuart and co-workers (Stuart et al., 1988, 1990) have recently produced stable lines of transgenic zebrafish by insertion of foreign DNA into the zebrafish genome; some of these lines express the genes encoded by the inserts. In the future, it should be possible to create mutations in genes that play important roles in neuronal development by insertion of foreign DNA into them. Such "insertional mutagenesis" has been used in the mouse to generate mutations that affect embryonic development by disrupting the function of the gene into which the foreign DNA integrated (Jaenisch et al., 1983; Woychik et al., 1985). An important advantage of this technique is that, because the inserted DNA sequences are known, a disrupted gene can easily be cloned. Moreover, recent work in the mouse suggests that it may soon bc feasiblc to target forcign DNA to specific sites and thus mutate particular genes (Capecchi, 1987). Thus, it may be possible, for example, to learn the functions of vertebrate homologues of developmentally important genes from Drosophila (Kessel and Gruss, 1990). The accessibility of the 
zebrafish embryo for observations and manipulations and the similarities between its development and that of other vertebrates (reviewed in Kimmel, 1989) make it an attractive species for studying the mechanisms of nervous system development.

\section{References}

Bastiani MJ, Doe CQ, Helfand SL, Goodman CS (1985) Neuronal specificity and growth cone guidance in grasshopper and Drosophila embryos. Trends Neurosci 8:257-266.

Bate M, Goodman CS, Spitzer NC (1981) Embryonic development of identified neurons: segment-specific differences in the $\mathrm{H}$ cell homologues. J Neurosci 1:103-106.

Bentley D, Caudy M (1983) Navigational substrates for peripheral pioneer growth cones: limb-axis polarity cues, limb-segment boundaries, and guidepost neurons. Cold Spring Harbor Symp Quant Biol 48:573-585.

Capecchi MR (1987) Altering the genome by homologous recombination. Science 244:1288-1292.

Chakrabarti S, Streisinger G, Singer F, Walker C (1983) Frequency of $\gamma$-ray induced specific locus and recessive lethal mutations in mature germ cells of the zebrafish, Brachydanio rerio. Genetics 103:109-123.

Chalfie M, Au M (1989) Genetic control of differentiation of the Caenorhabditis elegans touch receptor neurons. Science 243:1027-1033.

Desai C, Garriga G, McIntire SL, Horvitz HR (1988) A genetic pathway for the development of the Caenorhabditis elegans HSN motor neurons. Nature 336:638-646.

Doe CQ, Scott MP (1988) Segmentation and homeotic gene function in the developing nervous system of Drosophila. Trends Neurosci 11: 101-106.

Eiken HG, Njolstad PR, Molven A, Fjose A (1987) A zebrafish homcobox-containing gene with embryonic transcription. Biochem Biophys Res Commun 149:1165-1171.

Eisen JS (1989) Soma position determines identity of primary motoneurons in developing zebrafish embryos. Soc Neurosci Abstr 15: 1262.

Eisen JS, Myers PZ, Westerfield M (1986) Pathway selection by growth cones of identified motoneurons in live zebrafish embryos. Nature 320:269-271.

Eisen JS, Pike SH, Debu B (1989) The growth cones of identified motoneurons in embryonic zebrafish select appropriate pathways in the absence of specific cellular interactions. Neuron 2:1097-1 104.

Eisen JS, Pike SH, Romancier B (1990) An identified neuron with variable fates in embryonic zebrafish. J Neurosci 10:34-43.

Faber DS, Korn H (1978) Neurobiology of the Mauthner cell. Ncw York: Raven.

Fjose A, Eiken HG, Njolstad PR, Molven A, Hordvik I (1988) I. A zebrafish engrailed-like homeobox sequence expressed during embryogenesis. FEBS Lett 231:355-360.

Frost D, Westerfield M (1986) Axon outgrowth of embryonic zebrafish neurons is promoted by laminin and inhibited by fibronectin. Soc Neurosci Abstr 12:1114.

Grunwald DJ, Kimmel CB, Westerfield M, Walker C, Streisinger G (1988) A neural degeneration mutation that spares primary neurons in the zebrafish. Dev Biol 126:115-128.

Hanneman E, Trevarrow B, Metcalfe WK, Kimmel CB, Westerfield M (1988) Segmental pattern of development of the hindbrain and spinal cord of the zebrafish embryo. Development 103:49-58.

Hatta K, Schilling TF, BreMiller RA, Kimmel CB (in press) Specification of jaw muscle identity in zebrafish: correlation with engrailedhomeodomain expression. Science, in press.

Ho RK, Kane DA (in press) The zebrafish spt-1 mutation acts cellautonomously in specific mesodermal precursors. Nature, in press.

Honig MG, Hume RI (1986) Fluorescent carbocyanine dyes allow living neurons of identified origin to be studied in long-term cultures. J Cell Biol 103:171-187.

Jaenisch R, Harbers K, Schnieke A, Lohler J, Chumakov I, Jahner D, Grotkoop D, Hoffmann E (1983) Germline integration of Moloney murine leukemia virus at the Mov 13 locus leads to recessive lethal mutation and early embryonic death. Cell 32:209-216.

Keshishian H, Bentley D (1983) Embryogenesis of peripheral nerve pathways in grasshopper legs. Dev Biol 96:116-124.

Kessel M, Gruss M (1990) Murine developmental control genes. Science 249:374-379.
Keynes RJ, Lumsden A (1990) Segmentation and the origin of regional diversity in the vertebrate nervous system. Neuron 2:1-9.

Keynes RJ, Stern CD (1984) Segmentation in the vertebrate nervous systcm. Nature 310:786-789.

Kimmel CB (1989) Genetics and early development of zebrafish. Trends Genet 5:283-288.

Kimmel CB (1990) Embryonic origins of segmented nervous systems. In: Molecular approaches toward supracellular phenomena (Roth S, ed), pp 136-174. Philadelphia: University of Pennsylvania Press.

Kimmel CB, Law RD (1985a) Cell lineage of zebrafish blastomeres. I. Cleavage pattern and cytoplasmic bridges between cells. Dev Biol 108:78-85.

Kimmel CB, Law RD (1985b) Cell lineage of zebrafish blastomeres. II. Formation of the yolk syncytial layer. Dev Biol 108:86-93.

Kimmel CB, Warga RM (1986) Tissue-specific cell lineages originate in the gastrula of the zebrafish. Science 231:365-368.

Kimmel CB, Warga RM (1987) Indeterminate cell lineage of the zebrafish embryo. Dev Biol 124:269-280.

Kimmel CB, Westerfield M (1990) Primary neurons of the zebrafish In: Signals and sense: local and global order in perceptual maps (Edelman GM, Gall WE, Cowan WM, eds), pp 561-588. New York: Wiley.

Kimmel CB, Powell SL, Metcalfe WK (1982) Brain neurons which project to the spinal cord in young larvae of the zebrafish. J Comp Neurol 205:112-127.

Kimmel CB, Kane DA, Walker C, Warga RM, Rothman MB (1989) A mutation that changes cell movement and cell fate in the zebrafish embryo. Nature 337:358-362.

Kimmel CB, Warga RM, Schilling TF (1990) Origin and organization of the zebrafish fate map. Development 108:581-594.

Kuwada JY (1986) Cell recognition by neuronal growth cones in a simple vertebrate embryo. Science 233:740-746.

Kuwada JY, Bernhardt RR, Chitnis AB (1990) Pathfinding by identified growth cone in the spinal cord of zebrafish embryos. J Neurosci 10:1299-1308.

Lewis J, Chevallier A, Kieny M, Wolpert L (1981) Muscle nerve branches do not develop in chick wings devoid of muscle. J Embryol Exp Morphol 64:211-232.

Liu DWC, Westerfield M (1990) The formation of terminal fields in the absence of competitive interactions among primary motoneurons in the zebrafish. J Neurosci 10:3947-3959.

Loer CM, Jellies J, Kristan WB Jr (1987) Segment-specific morphogenesis of leech Retzius neurons requires particular peripheral targets. J Neurosci 7:2630-2638.

Lumsden A, Keynes R (1989) Segmental patterns of neuronal development in the chick hindbrain. Nature 337:424 428 .

Mendelson B (1986a) Development of reticulospinal neurons of the zebrafish. I. Time of origin. J Comp Neurol 251:160-171.

Mendelson B (1986b) Development of reticulospinal neurons of the zebrafish. II. Early axonal outgrowth and cell body position. J Comp Neurol 251:172-184.

Metcalfe WK (1985) Sensory neuron growth cones comigrate with posterior lateral line primordial cells in zebrafish. J Comp Neurol 238:218-224.

Metcalfe WK, Mendelson B, Kimmel CB (1986) Segmental homologies among reticulospinal neurons in the hindbrain of the zebrafish larva. J Comp Neurol 251:147-159.

Metcalfe WK, Myers PZ, Trevarrow B, Bass MB, Kimmel CB (in press) Primary neurons that express the L2/HNK-1 carbohydrate during early development in the zebrafish. Development, in press.

Molven A, Wright CVE, BreMiller R, De Robertis EM, Kimmel CB (1990) Expression of a homeobox gene product in normal and mutant zebrafish embryos: evolution of the tetrapod body plan. Development 109:279-288.

Myers PZ (1985) Spinal motoneurons of the larval zebrafish. J Comp Neurol 236:555-561.

Myers PZ, Eisen JS, Westerfield M (1986) Development and axonal outgrowth of identified motoneurons in the zebrafish. J Neurosci 6: 2278-2289.

Njolstad PR, Fjose A (1988) In situ hybridization patterns of zebrafish homeobox genes homologous to $\mathrm{Hox}-2.1$ and $F N-2$ of mouse. Biochem Biophys Res Commun 157:426-432.

Njolstad PR, Molven A, Eiken HG, Fjose A (1988a) Structure and neural cxpression of a zebrafish homeobox sequence. Gene 73:3346. 
Njolstad PR, Molven A, Fjose A (1988b) A zebrafish homologue of the murine Hox-2. gene. FEBS Lett 230:25-30.

Patel NH, Martin-Blanco E, Coleman KG, Poole SJ, Ellis MC, Kornberg TB, Goodman CS (1989) Expression of engrailed proteins in arthropods, annelids, and chordates. Cell 58:955-968.

Patterson PH (1988) On the importance of being inhibited, or saying no to growth cones. Neuron 1:263-267.

Pike SH, Eisen JS (1990) Interactions between identified motoneurons in embryonic zebrafish are not required for normal motoneuron development. J Neurosci 10:44-49.

Pike SH, Brandenburg EF, Eisen JS (1989) Extension of motoneuronal growth cones is disrupted by the absence of pre-existing axonal pathways. Soc Neurosci Abstr 15:1262.

Purves D, Lichtman JW (1985) Principles of neural development. Sunderland, MA: Sinauer.

Rogers SL, Letourneau PC, Palm SL, McCarthy J, Furcht LT (1983) Neurite extension by peripheral and central nervous system neurons in response to substratum-bound fibronectin and laminin. Dev Biol 98:212-220.

Stern CD, Kcyncs RJ (1988) Spatial patterns of homeobox gene expression in the developing mammalian CNS. Trends Neurosci 11: 190-192.

Streisinger $G$ (1984) Attainment of minimal biological variability and measurements of genotoxicity: production of homozygous diploid zebra fish. Natl Cancer Inst Monogr 65:53-58.

Streisinger G, Walker C, Dower N, Knauber D, Singer F (1981) Production of clones of homozygous diploid zebra fish (Brachydanio rerio). Nature 291:293-296.

Streisinger G, Singer F, Walker C, Knauber D, Dower N (1986) Segregation analyses and gene-centromere distances in zebrafish. Genetics 112:311-319.

Streisinger G, Coale F, Taggart C, Walker C, Grunwald DJ (1989) Clonal origins of cells in the pigmented retina of the zebrafish eye. Dev Biol 131:60-69.
Stuart GW, McMurray JV, Westerfield M (1988) Replication, integration and stable germ-line transmission of foreign sequences injected into early zebrafish embryos. Development 103:403-412.

Stuart GW, Vielkind JR, McMurray JV, Westerfield M (1990) Stable lines of transgenic zebrafish exhibit reproducible patterns of transgene expression. Development 109:577-584

Sulston JE, White JG (1980) Regulation and cell autonomy during postembryonic development of Caenorhabditis elegans. Dev Biol 78: 577-597.

Sulston JE, Schierenberg E, White JG, Thomas JN (1983) The embryonic lineages of the nematode Caenorhabditis elegans. Dev Biol 100:64-119.

Thorogood P, Wood A (1987) Analysis of in vivo cell movement in transparent tissue systems. J Cell Sci [Suppl] 8:395-413.

Tosney KW (1987) Proximal tissues and patterned neurite outgrowth at the lumbosacral level of the chick embryo: deletion of the dermamyotome. Dev Biol 122:540-558.

Trevarrow B, Marks DL, Kimmel CB (1990) Organization of hindbrain segments in the zebrafish embryo. Neuron 4:669-679.

Walker C, Streisinger G (1983) Induction of mutations by $\gamma$-rays in pregonial germ cells of zebrafish embryos. Genetics 103:125-136.

Westerfield M, Eisen JS (1985) The growth of primary motor axons in Xenopus embryos. Dev Biol 109:96-101.

Westerfield M, McMurray J, Eisen JS (1986) Identified motoneurons and their innervation of axial muscles in the zebrafish. J Neurosci 6 : 2267-2277.

Westerfield M, Kimmel CB, Walker C, Liu DW (1990) Pathfinding and synapse formation in a zebrafish mutant lacking acetylcholine receptors. Neuron 4:867-874.

Wilson SW, Ross LS, Parrett T, Easter SS Jr (1990) The development of a simple scaffold of axon tracts in the brain of the embryonic zebrafish, Brachydanio rerio. Development 108:121-145.

Woychik RP, Steward TA, Davis LG, D'Eustachio R, Leder P (1985) An inherited limb deformity created by insertional mutagenesis in a transgenic mouse. Nature 318:36-40. 